\title{
Apropiación de las tecnologías móviles desde una espejo lejano: infiltración barroca, creolización y canibalismo: una reseña
}

\author{
Alejandra Davidziuk \\ < adavidziuk@,comunica.org >
}

En este trabajo, los autores ${ }^{1}$ usan la evocativa sugerencia del Manifiesto Antropófago brasileño para considerar la apropiación de las tecnologías móviles y sus contribuciones a fin de repensar el impacto público de esos dispositivos en América Latina. El argumento central del Manifiesto entiende "felicidad" como un motor de desarrollo comunitario (llamado también "cultura viva") que debería ser transformado en política pública efectivamente apropiada por su gente. En ese sentido, Bar et al. sugieren analizar cómo la gente usa los teléfonos móviles a fin de demostrar que esos dispositivos tecnológicos pueden ser considerados como herramientas para el desarrollo y el cambio cultural.

Este trabajo de investigación del lado de la demanda no sólo examina cómo la apropiación tecnológica tiene lugar bajo diferentes circunstancias históricas, culturales y económicas en América Latina, sino que realiza otros esfuerzos conexos para explicar la importancia de la apropiación tecnológica y diversos enfoques para analizarla. Luego de primeramente considerar y comparar los pro y contra de los tres enfoques tradicionales de apropiación (pro-social; discursivo; y técnico), profundiza una línea teórica alternativa basada en la noción de "aprender mediante el hacer" y "aprender mediante el uso". El segundo esfuerzo es la presentación de diferentes modos de apropiación cultural en América Latina, relacionando su diversidad con una multiplicidad de estrategias de resistencia y apropiación. En dicha sección, los autores introducen tres modos culturales arquetípicos de apropiación tecnológica (barroquismo, creolización y canibalismo) que se remontan a hechos específicamente brasileños pero intentan ser aplicados a un contexto más amplio. El tercer y último esfuerzo propone un marco teórico para conectar los modos culturales de apropiación tecnológica con un proceso cíclico de tres niveles, que sucesivamente pasa por fases de adopción, apropiación y re-configuración. Esta conexión integra el propuesto enfoque de apropiación tecnológica basado en la noción de "aprender mediante el hacer" y subraya que el proceso de apropiación es fundamentalmente una negociación de poder y control sobre los artefactos. A modo de conclusión, los autores afirman que, a fin de conocer más sobre los mecanismos de innovación y el impacto de los teléfonos celulares, sería conveniente seguir analizando en detalle sobre la apropiación tecnológica en vez de concentrarse en las tasas de consumo. Estudiar la penetración tecnológica en forma aislada, dicen, sólo puede explicar una parte de la historia.

Este artículo contiene varias referencias a interesantes e informativas fuentes de investigación teórica sobre cómo la apropiación de teléfonos celulares en América Latina construye - re-produce - expresiones culturales específicas. De ese modo, los autores presentan un particular marco teórico para analizar el impacto social, económico y político de los teléfonos móviles en la región - basándose en tres modos culturales de apropiación tecnológica: barroquismo, creolización y canibalismo. De acuerdo a los autores, estos tres modos exhiben diferentes niveles de confrontación y evolución durante el proceso cíclico que comprende tres instancias: adopción, apropiación y re-configuración entre el usuario y el proveedor de la tecnología. Esta confrontación supone negociar "poder y control sobre la configuración de la tecnología, sus usos y la distribución de sus beneficios."

1 François Bar, Francis Pisani, Matthew Weber, preparado para discusión en el Seminario sobre Desarrollo Económico, Desarrollo Social y Comunicaciones Móviles en América Latina. Organizado por la Fundación Telefónica en Buenos Aires, Abril 20-21, 2007. François Bar y Matthew Weber pertenecen a la Annenberg School of Communication, University of Southern California. Francis Pisani es parte del Instituto Tecnológico Autónomo de México. 
Aunque el artículo explica que los dos grupos de tres componentes están interconectados, hubiera sido sumamente importante distinguir mejor que cada uno está basado en factores diferentes y apuntan a distintos objetivos. Mientras los modos culturales de apropiación tecnológica están relacionados con los diversos antecedentes individuales y el potencial creativo que los individuos y comunidades tienen, el proceso cíclico de evolución tecnológica está conectado con un diálogo social que, a su vez, está redefinido por ciertas relaciones de poder y control.

La forma en que estos tres modos de apropiación tecnológica tiene lugar es arbitrario y depende de las capacidades y estrategias de innovación que cada individuo o comunidad pueda desarrollar. Por ejemplo, los usuarios barrocos tenderían a seguir manuales y personalizar sus teléfonos de acuerdo a las recomendaciones de los proveedores. Los usuarios creolizados irían un poco más lejos, recombinando los artefactos originales con otros componentes dando por resultado algo nuevo (una suerte de bricolage). Los usuarios caníbales, en cambio, desmantelan, destruyen y/o ocultan el artefacto original para crear algo nuevo que represente mejor quiénes son y qué sienten.

El punto central del marco teórico apunta al momento de apropiación y re-invención, en el que la tecnología es alterada en un proceso de "aprender haciendo". Esto puede ser un momento tranquilo o una escalada confrontación para ganar poder. Usar el teléfono celular para realizar llamadas o enviar mensajes de texto, por ejemplo, es el primer paso para conocer lo que los fabricantes de tecnología han dejado en las góndolas de los negocios. Luego, según los autores, los usuarios deberían estimular su ingenio para plantear "relaciones cooperativas" entre ellos y los fabricantes para establecer un espacio de aprendizaje que beneficie a ambos.

\section{La alegría no es sólo brasileña - América Latina en perspectiva}

El artículo resulta muy interesante en términos de revisión bibliográfica y el modo en que los autores justifican los canales de negociación en cada modo de apropiación, sin embargo, el marco teórico necesitaría ser complementado con más estudio empírico que permita analizar y evaluar el impacto de la tecnología en la región. Los datos cualitativos son muy valiosos pero imposibles para generalizar y emplear en estudios comparativos. Una posible solución podría ser establecer bases para un estudio de caso sobre los usos de telefonía celular en lugares remotos y marginales de América Latina. Dichos estudios deberían explorar cómo esta tecnología de telefonía celular impacta en los diferentes tipos de "felicidad" o "cultura viva" que cada comunidad o grupo detenta.

América Latina cuenta con una diversa población con desigual acceso a las oportunidades para apropiarse de los servicios básicos. Pobres y ricos tiene modos de apropiación tecnológica completamente diferente. Aunque ambos comparten la fascinación por nuevos equipos y participan de distinta forma en las tres etapas de evolución tecnológica que los autores presentan, más allá del consumo, los grupos económicamente más carenciados no tienen posibilidad de negociar con las corporaciones u obtener beneficios del diálogo de aprendizaje. A mi juicio, los hackers son uno de los únicos grupos privilegiados en poner la fase de canibalismo en práctica debido a sus habilidades particulares y el gran 
interés que las corporaciones tienen en lo que ellos pueden llegar a hacer o producir. Un ejemplo de esto fue el iPhoneDevCamp, donde 300 hackers se dieron cita en julio de 2007 en San Francisco, Estados Unidos, para descifrar entre todos los misterios del iPhone en un entorno libre de sanciones de Apple. Como lo describió el sitio Aboporu, la reunión de hackers fue una vívida reunión antagonista de variedad caníbal ${ }^{2}$.

Es evidente que los teléfonos celulares ya no son más un artefecto de lujo ni de elite (debido a su altas tasas de penetración ${ }^{3}$ ) pero no quedan claros los diferente beneficios sociales, económicos y políticos que los mismos pueden producir. Esa es la razón, sumada a los patrones diversos y asimétricos latinoamericanos, para realizar diferentes tipos de estudios e investigaciones complementarias para echar luz en cómo la tecnología móvil puede impactar en la vida de la gente y, a su vez, las distintas formas en que la gente incorpora las tecnologías a su vida, negociando dinámicas culturales y de poder en el proceso.

El artículo también invita a pensar acerca de qué tipo de implicaciones de política podría tener la apropiación de tecnología móvil en general y de la telefonía celular en particular. Desde el lado de la oferta, pareciera mucho más claro imaginar las acciones a implementar por funcionarios y los reguladores de telecomunicaciones a fin de maximizar una industria que crece cada año. Promover la inversión para que los operadores expandan sus redes y concentrarse en aquellas políticas que faciliten la penetración son las acciones principales que han sido aplicadas en la región en la última década. ¿Cómo esas decisiones impactan en la apropiación cultural individual y comunitaria de los teléfonos móviles en América Latina? Sería interesante explorar las implicancias que el proceso cíclico de tres fases de evolución tecnológica podría tener. Las preguntas claves a realizar incluirían: ¿Cómo se establecen las negociaciones de reconfiguración? ¿Quiénes participarían de esas negociaciones y bajo qué condiciones? ¿Quién controlaría las nuevas ideas y descubrimientos (copyright o creative commons)? ¿La re-configuración tecnológica es una acción individual o colectiva? ¿Cómo esos intercambios podrían evolucionar para terminar confirmando un proceso de aprendizaje?

El único obstáculo que encontré en el artículo para analizar las implicaciones de políticas es que un actor clave está complemente ausente: el sector público. ¿Qué clase de rol tendrían los Estados en esas “negociaciones” entre usuariosproveedores que los autores proponen? ¿Los consumidores latinoamericanos estarían preparados para tomar un rol activo en esa clase de confrontación? ¿Las corporaciones estarían preparadas para recibir las opiniones de consumidores y reguladores sobre sus productos?

\section{NOTA}

* Este artículo está basado en un documento anterior "Cannibalism, creolization and baroque mobile use," escrito por Alejandra Davidziuk y publicado en Regulateonline.org el 16 de agosto de 2007

\footnotetext{
2 Ver el sitio Abaporu (http://abaporu.wordpress.com/2007/07/10/agonantagon-appropriation-as-theater/)

3 En América Latina, 300 millones de personas eran propietarias de un teléfono celular en 2005 (sólo 4 millones en 1995). Las redes inalámbricas suministraron una cobertura del $80 \%$ durante ese mismo año. "En América Latina, la telefonía celular suministra la única fuente de acceso a algunos de los segmentos más pobres de la población y se ha convertido en el modo de comunicación predominante." Justamente, la telefonía celular ha sido la que ha crecido más en los últimos cinco años. http://www.regulateonline.org/content/view/898/69/
} 